\title{
A SWOT Analysis of Indonesia's COVID- 19 Pandemic Response Strategy
}

\author{
Dicky Budiman ${ }^{1}$ and Cordia $\mathrm{Ch}^{2}$ \\ ${ }^{1}$ Medical Doctor, Epidemiologist and PhD Candidate, Centre for Environment and Population Health, Griffith University, Brisbane, Australia.
${ }^{2}$ Director, Centre for Environment and Population Health Griffith University, Brisbane, Australia.
Corresponding author: Dicky Budiman (e-mail: drdickybudiman@ @mail.com).
}

INDEX TE RMS COVID-19, Pandemic, SWOT analysis, Indonesia's strategy, letter to editor.

The COVID-19 pandemic as public health crisis has shown the world was unprepared, unanticipated and ill-equipped to handle the crisis. As a consequence, it turned into a social, economic, and political emergency. Indonesia, like others countries of the world, has no exception. The government declared the first case of COVID-19 in Indonesia on March 2, 2020, and the President declared the state of health emergency on March 31, 2020 [1]. Positif progress of COVID-19 pandemic seen in last quarter of 2021, after a series of measures, including significant social restrictions, indicated that the interventions successfully reduced the spread of the virus nationally and prevented the worst scenario of the crisis during Indonesia's COVID-19 second wave, July 2021. Following the significant public health and social restriction, the gradual step-wise lifting of social and economic activities. Indonesia's response underwent a dynamic change during the pandemic.

An analysis of Indonesia's preparedness and response strategies' strengths, weaknesses, opportunities and threats (SWOT) has been conducted based on literature review, interviews with resource persons, and online focus group discussion. A SWOT analysis effectively reviews public health response to pandemic COVID-19 in China, India, Iran, Italia, Japan, Morocco and UAE [2-8]. A brief SWOT analysis of strategic response in Indonesia is given, with main highlights in each category. The analysis results are helpful to give a constructive critical analysis of the current potency, problems, strategies and draw lessons during pandemic COVID-19 in Indonesia (FIGURE 1).

Indonesia successful respon to the COVID-19 pandemic shows its main strength factors. First, the Indonesian government took a lesson from its first year of pandemic response by strengthening joint actions among government bodies and immediate enhancing public health measures to contain, reduce, and prevent the COVID-19. Effective implementation of public health and social restriction followed by a phased relaxation by the Indonesian government slowed the spread of the COVID-19 epidemic in Indonesia. Second, Indonesia's early response to vaccine diplomacy ensured the earliest access to the COVID-19 vaccines compared to many developing countries. Third, the government has utilised the existing public infrastructure such as schools, hotels, offices, and buildings not in use as either isolation wards or quarantine centres. Fourth, the Indonesian tradition includes joint burdens by helping each other, or mutual assistance (gotong-royong) plays an essential role in community resilience. Moreover, the enthusiasm, motivation and sacrifice of the health workforce, volunteers, and community in the face of calamity were encouraging.

However, as expected, the COVID-19 pandemic exposed more weaknesses than Indonesia's health system strengths. At first, it was about risk communication, even though, as soon as the government announced the first case, a daily press briefing was broadcast live through national television channels, the risk communication strategy was not implemented effectively during the crisis. Lack of communication between line ministries and leaders often leads to more confusing directions to sub-national levels. On the other hand, though the second year of the pandemic has shown more proactive leadership and transparent initiatives, leadership and governance are still the issues faced at national and sub-national levels. The third weakness factor is the lack of public health infrastructure, especially in rural areas and out of Java-Bali island. The rapid expansion of existing healthcare 


\section{A SWOT ANALYSIS OF INDONESIA'S COVID-19 MANAGEMEN}

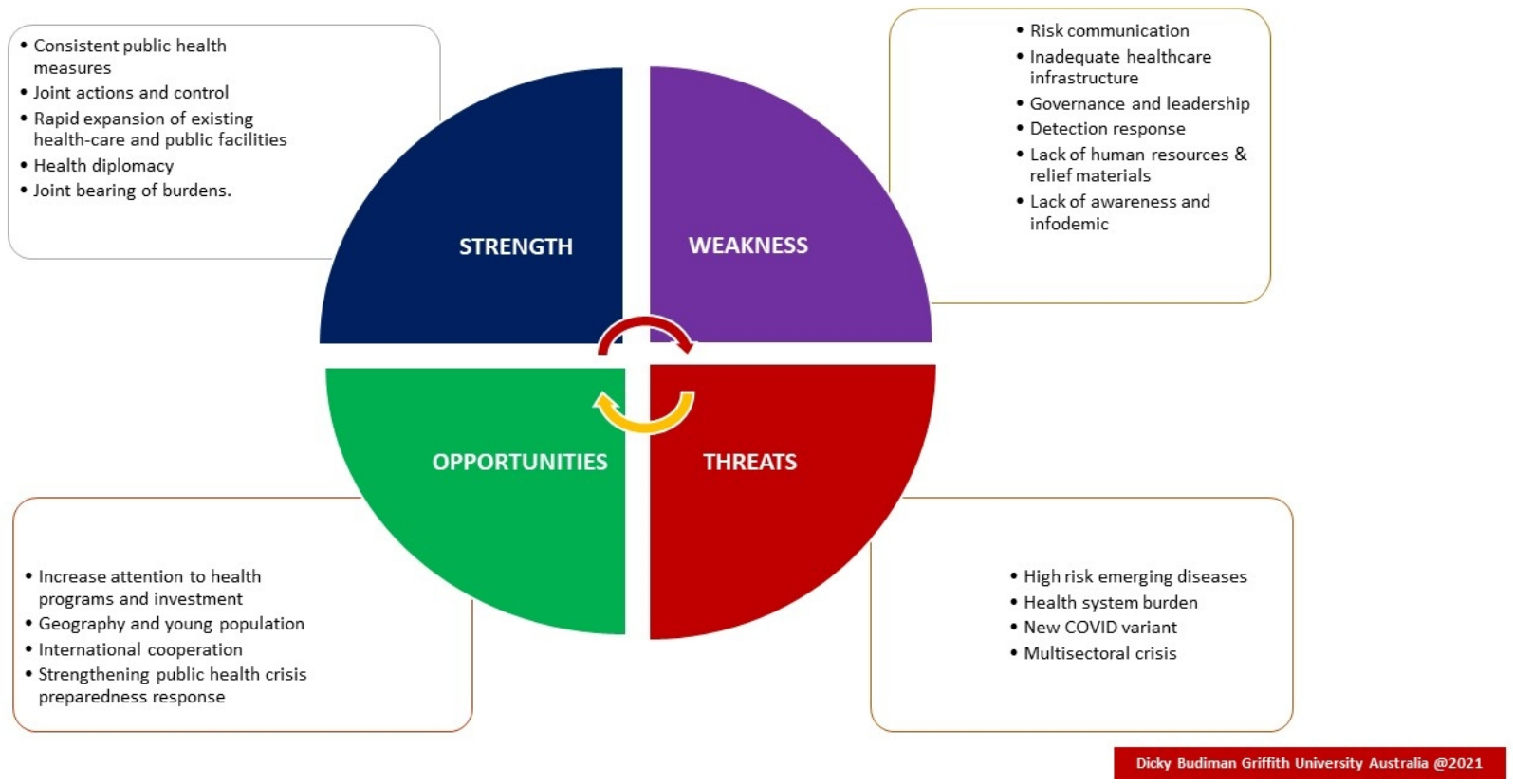

FIGURE 1. A SWOT Analysis of Indonesia's COVID-19 managemen

facilities is not adequate to meet the crisis. The pandemic exposed the absence of working primary healthcare facilities in rural and urban slums areas. There were also many inequities as far as availability, accessibility, and affordability of the services are concerned.

Fourth, the strategy intervention focused more on curative rather than prevention and early detection. COVID-19 vaccine is getting more attention after its release in January 2021, and the government has prioritised it in dealing with the crisis [9]. Meanwhile, people believe that it is the only solution to the pandemic. In addition, the euphoria of the vaccination program caused the abandonment of public health measures which led to another wave of pandemics. The fifth weakness of the crisis is the lack of human resources, poor supply chain, and health relief. This pandemic emphasised a need for a dedicated health workforce, but relatively inadequate primary and secondary healthcare infrastructure and staffing in many areas led to overburdened health staff. The problem is more aggravated due to inequitable distribution, public health facilities, and lack of specialist and service provisions at health facilities. The availability and sustainability of oxygen, medicines, diagnostic kits, relief materials, and personal protective equipment became critical during the calamity stages. The last weakness is the rise of the simultaneous fear pandemic through social media, spreading misinformation and rumours. The spread of fake news and miscommunication in society from untrusted sources of information has led to despair and fear. There were few experts from public health and epidemiology were involved from the beginning of the pandemic. As a result, the infodemic was circulated fast without adequate countermeasures. The rise of selfproclaimed health experts in social media has created more fear and panic in public.

Regarding the opportunity aspect, there is some strong signal. First, the public health program is now getting the attention it deserves. It brings the possibility of increased investment in health sectors by the government and the implementation of health in all policies framework. The other attention also came from the community, which made them more aware of basic personal hygiene-related practices such as handwashing, practising social distancing, and using personal protection. In other words, this crisis has allowed improving other critical environmental health issues, such as pollutions, sanitation and avoiding open-air defecation. In addition, the pandemic is an excellent opportunity to create awareness about the prevention and control of other communicable diseases that remain a public health problem in Indonesia, such as tuberculosis, malaria, HIV and AIDS, and non-communicable diseases that are still present. Indonesia's second opportunity is its young population and its status as an archipelago country, which has significant consequences in influencing mobilisation. The seas between the islands of an archipelago are like natural isolation to separate those islands from each other. Then, the young population has a benefit in terms of their immunity respon and ability to recover from infection. Third, the COVID-19 opportunity is strengthening international, national and local cooperation among development partners, non-government organisations, professional organisations, public and other private institutions essential for developing public health emergency 
preparedness and response plans and standard operating policies and procedures for potential future pandemics. The improvement can also include developing a systematic training network of healthcare providers and health workforce, strengthening primary healthcare facilities, and upgrading existing public health facilities. Furthermore, as a global citizen, Indonesia should take a role in actively pushing global cooperation in managing the global health crisis.

Every nation should monitor and manage the other public health threats to gain sustainable progress in pandemic management and speed up the recovery. The first threat is a burden to the health system if the nation put the COVID-19 as a solely public health problem, neglecting other public health issues and causing new public health problems. Many research has found an increased rate of non-communicable diseases and mental health problems during the COVID-19 pandemic because people stay at home and become inactive. Less attention to non-COVID patients and neglecting the needs of non-COVID health services will again lead to more health system burden. In addition, as the hot spot of emerging and reemerging diseases, Indonesia should maintain its surveillance and diseases control program across the nation [10]. The second is a multidimensional crisis when the nation fails to pay attention to any social determinants of health to prevent its detrimental effect on the economy and overall growth of the nation. COVID-19 pandemic is a multisectoral crisis that needs multisectoral and global collaboration, and all sectors are necessary for the country's overall socio-economic development. The third threat is a new COVID-19's super variant, which is resistant to vaccines and treatment. The management of emerging variants has to do with early detection, vaccination coverage and surveillance. Testing, tracking and isolating quarantine strategies is the core of countries pandemic response. In addition, the slower countries vaccinate the population most at risk of spreading the disease, the more variants will emerge. Finally, surveillance and whole-genome sequencing can identify the mutations and trace the transmission of variants between individuals, populations and nations.

Undeniably, the COVID-19 pandemic proved to be an examination for Indonesia's public health system and other sectors. The strength and weaknesses come to the fore amid the COVID-19 pandemic. Furthermore, COVID-19 is a public health crisis, and it is the perfect time to retrospectively analyse health capacity and other related factors. The government and public have already learnt a lot in the response, what works and what does not. Therefore, the government should undertake a comprehensive and localbased SWOT analysis at the provincial and district levels. The SWOT analysis would be helpful in the current response and prepare for any other global health security threat; from all these experiences, Indonesia will be better prepared to deal with a similar or worse situation in the future.

\section{REFERENCES}

1. COVID-19 developments in Indonesia [Internet]. AHK Indonesien. [cited 2021 Nov 25]. Available from: https://indonesien.ahk.de/en/infocenter/news/news-details/covid-19developments-in-indonesia

2. Wang J, Wang Z. Strengths, Weaknesses, Opportunities and Threats (SWOT) Analysis of China's Prevention and Control Strategy for the COVID-19 Epidemic. Int J Environ Res Public Health [Internet]. 2020 Jan [cited 2021 Nov 23];17(7):2235. Available from: https://www.mdpi.com/1660-4601/17/7/2235

3. Shimizu K. A SWOT Analysis of the Guidelines on Prevention of HIV/AIDS in Japan in the Context of COVID-19. Infect Dis Rep [Internet]. 2021 Dec [cited 2021 Nov 23];13(4):949-56. Available from: https://www.mdpi.com/2036-7449/13/4/87

4. Thakur H. A Strengths, Weaknesses, Opportunities, and Threats Analysis of Public Health in India in the Context of COVID-19 Pandemic. Indian J Community Med Off Publ Indian Assoc Prev Soc Med [Internet]. 2021 [cited 2021 Nov 23];46(1):1-3. Available from: https://www.ncbi.nlm.nih.gov/pmc/articles/PMC8117898/

5. Barkia A, Laamrani H, Belalia A, Benmamoun A, Khader Y. Morocco's National Response to the COVID-19 Pandemic: Public Health Challenges and Lessons Learned. JMIR Public Health Surveill [Internet]. 2021 Sep 17 [cited 2021 Nov 23];7(9):e31930. Available from: https://publichealth.jmir.org/2021/9/e31930

6. Abbas Zaher W, Ahamed F, Ganesan S, Warren K, Koshy A. COVID19 Crisis Management: Lessons From the United Arab Emirates Leaders. Front Public Health [Internet]. 2021 Oct 29 [cited 2021 Nov 23];9:724494. Available from: https://www.ncbi.nlm.nih.gov/pmc/articles/PMC8585940/

7. Torri E, Sbrogiò LG, Di Rosa E, Cinquetti S, Francia F, Ferro A Italian Public Health Response to the COVID-19 Pandemic: Case Report from the Field, Insights and Challenges for the Department of Prevention. Int J Environ Res Public Health [Internet]. 2020 Jan [cited 2021 Nov 23];17(10):3666. Available from: https://www.mdpi.com/1660-4601/17/10/3666

8. Sajadi H, Hartley K. COVID-19 pandemic response in Iran: a dynamic perspective on policy capacity. J Asian Public Policy [Internet]. 2021 Jun 2 [cited 2021 Nov 23];0(0):1-22. Available from: https://doi.org/10.1080/17516234.2021.1930682

9. Vaksinasi COVID-19 di Indonesia Dimulai, Nakes Takut Protokol Kesehatan Mengendur [Internet]. 2021 [cited 2021 Nov 25]. Available from: https://www.abc.net.au/indonesian/2021-01-13/vaksinasicovid-19-dimulai-jokowi-jadi-orang-pertama-disuntik/13050392

10. Coker RJ, Hunter BM, Rudge JW, Liverani M, Hanvoravongchai P. Emerging infectious diseases in southeast Asia: regional challenges to control. Lancet Lond Engl [Internet]. 2011 [cited 2021 Nov 25];377(9765):599-609. Available from: https://www.ncbi.nlm.nih.gov/pmc/articles/PMC7159088/ 